\title{
Polyamines and related signaling pathways in cancer
}

\author{
Jiajing $\mathrm{Li}^{1,2}$, Yan Meng ${ }^{2}$, Xiaolin $\mathrm{Wu}^{2}$ and Yuxin Sun ${ }^{1 *}$ (])
}

\begin{abstract}
Polyamines are aliphatic compounds with more than two amino groups that play various important roles in human cells. In cancer, polyamine metabolism dysfunction often occurs, and regulatory mechanisms of polyamine. This review summarizes the existing research on the metabolism and transport of polyamines to study the association of oncogenes and related signaling pathways with polyamines in tumor cells. Drugs that regulate enzymes have been developed for cancer treatment, and in the future, more attention should be paid to treatment strategies that simultaneously modulate polyamine metabolism and carcinogenic signaling pathways. In addition, the polyamine pathway is a potential target for cancer chemoprevention. As an irreversible suicide inhibitor of the ornithine decarboxylase (a vital enzyme of polyamine synthesis), Difluoro-methylornithine had been shown to have the chemoprevention effect on cancer. Therefore, we summarized and analyzed the chemoprophylaxis effect of the difluoromethylornithine in this systematic review.
\end{abstract}

Keywords: Polyamine, Cancer, Metabolism, Signaling pathway, Oncogene, ODC, SSAT, DFMO

\section{Background}

Polyamines are polycationic alkylamines commonly found in all living cells, of which the most common are putrescine, spermine, and spermine (in millimolar concentrations) $[1,2]$. The flexibility in their charge distribution allows polyamines to combine with various negatively charged macromolecules, including DNA, RNA, proteins, and acidic phospholipids $[3,4]$. Therefore, they play an important role in cell growth, proliferation, differentiation, migration, gene regulation, and the synthesis of proteins and nucleic acids, in addition to maintaining chromatin structure, regulating ion channels, maintaining membrane stability, and scavenging free radicals [5-7]. It has been shown that increased intracellular polyamine concentrations are associated with cell proliferation and tumorigenesis [8-14]. Polyamine metabolism is often dysregulated in cancers. In addition,

*Correspondence: sunyux@jlu.edu.cn

${ }^{1}$ Department of Otorhinolaryngology-Head and Neck Surgery, ChinaJapan Union Hospital, Jilin University, Changchun, Jilin Province, China

Full list of author information is available at the end of the article the polyamine pathway is a downstream target for many oncogenes [15-17]. In normal physiological conditions, polyamines are regulated by a complex network of biosynthesis, catabolism, and transport systems (Fig. 1).

\section{Polyamine synthesis and metabolism Polyamine biosynthesis}

Excess nitrogen and ammonia produced by protein breakdown or nitrogen compound synthesis in vivo can be eliminated by the urea cycle. During this process, arginine is catalyzed by arginase to produce ornithine, the substrate for the synthesis of urea and polyamines. The main pathway of polyamine biosynthesis is the decarboxylation of ornithine catalyzed by ornithine decarboxylase (ODC) to generate putrescine. After that, spermidine and spermine are produced by the enzymatic transfer reaction of spermidine synthetase (encoded by $S R M$ ) and spermidine synthetase (encoded by $S M S$ ). The decarboxylation of s-adenosine methionine (dcAdoMet) catalyzed by $\mathrm{S}$-adenosine methionine decarboxylase (AdoMetDC; encoded by $A M D 1$ ) provides the aminopropyl donor for the above reactions [19-21]. 5'-methyl thio-adenosine

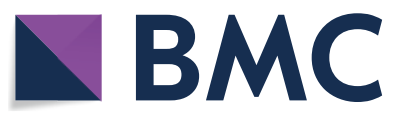

c) The Author(s) 2020. This article is licensed under a Creative Commons Attribution 4.0 International License, which permits use, sharing, adaptation, distribution and reproduction in any medium or format, as long as you give appropriate credit to the original author(s) and the source, provide a link to the Creative Commons licence, and indicate if changes were made. The images or other third party material in this article are included in the article's Creative Commons licence, unless indicated otherwise in a credit line to the material. If material is not included in the article's Creative Commons licence and your intended use is not permitted by statutory regulation or exceeds the permitted use, you will need to obtain permission directly from the copyright holder. To view a copy of this licence, visit http://creativeco mmons.org/licenses/by/4.0/. The Creative Commons Public Domain Dedication waiver (http://creativecommons.org/publicdomain/ zero/1.0/) applies to the data made available in this article, unless otherwise stated in a credit line to the data. 


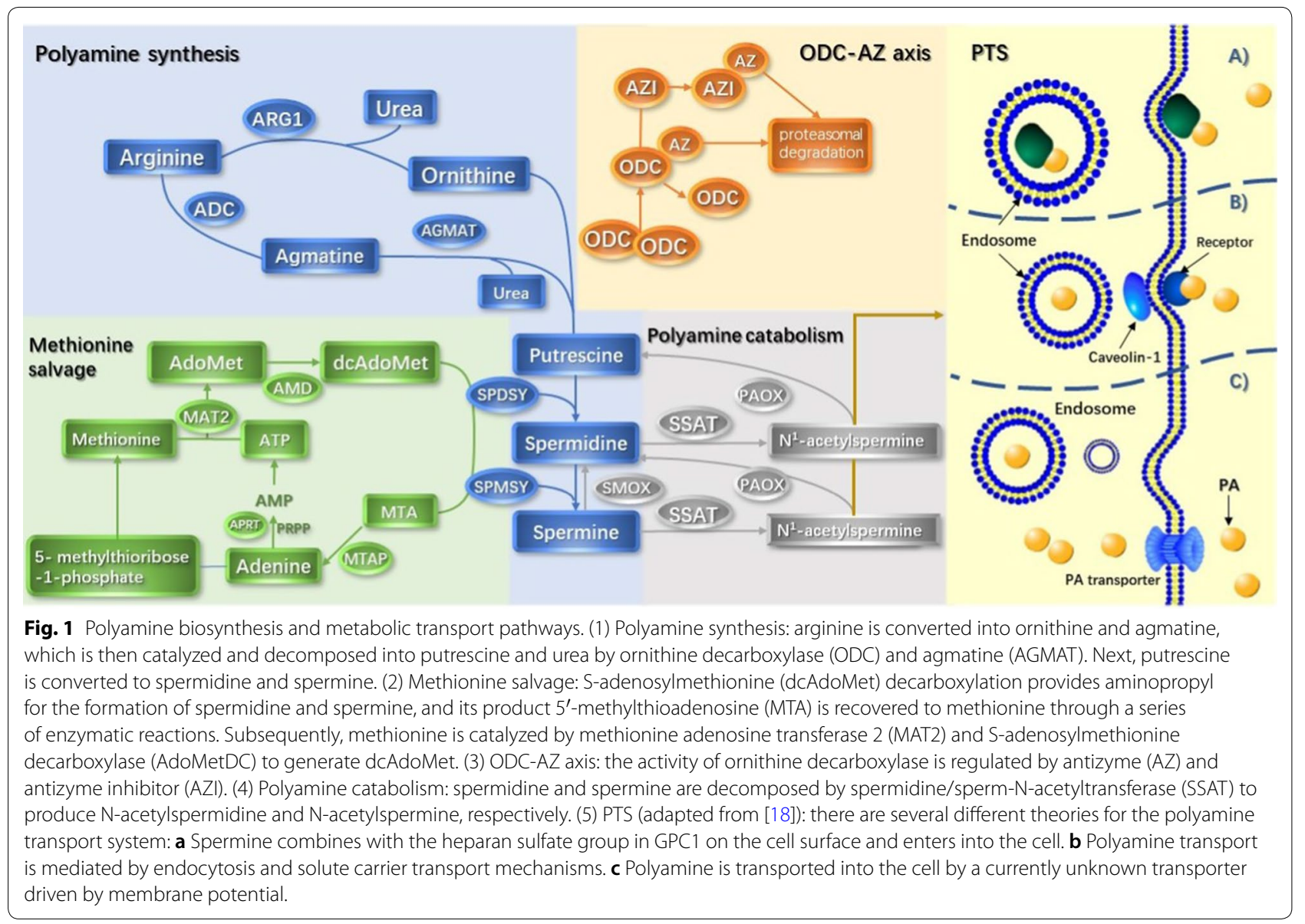

(MTA) is produced during spermine and spermine synthesis following the loss of dcAdoMet aminopropyl, which requires methionine recovery to methionine. MTA is converted to adenine and 5-methylthioribose1-phosphate by $5^{\prime}$-methylthioadenosine phosphorylase (MTAP). Methionine is extracted from 5-methylthioribose-1-phosphate to form a substrate that binds to ATP. It then interacts with methionine adenosyltransferase 2 (MAT2) to form S-adenosylmethionine (AdoMet). $\mathrm{S}$-adenosylmethionine provides aminopropyl for the production of spermidine and spermine [1, 22]. Recently, it was shown that arginine could be decarboxylated to produce agmatine in mammals, generating urea and putrescine under the action of agmatinase (AGMAT) [23].

Ornithine decarboxylase, a pyridoxal phosphatedependent enzyme, is the rate-limiting enzyme for polyamine synthesis. The activity of ODC in cancer cells is reported to be consistently increased, demonstrating its close relationship to the occurrence and development of tumors. ODC protein levels are regulated by a variety of stimuli, including hormones, growth factors, oncogenes, and free polyamines [19]. Anti enzyme (AZ) combines with ODC monomers to prevent it from forming an active homodimer, thereby promoting its ubiquitin-dependent degradation by the $26 \mathrm{~S}$ proteasome. AZ synthesis is influenced by antizyme inhibitor (AZI), a protein encoded by the $A Z I N 1$ gene. The structure of this protein is similar to ODC, but it binds AZ more closely than $\mathrm{ODC}$, thereby blocking the ability of $\mathrm{AZ}$ to inhibit ODC $[24,25]$.

\section{Polyamine catabolism}

The level of polyamine is also regulated by its catabolism, which can prevent the excessive levels of polyamine in cells [26]. Spermidine/spermine-N-acetyltransferase (SSAT) respectively acetylates spermidine and spermine to produce $\mathrm{N}$-acetylspermidine and $\mathrm{N}$-acetylspermine [27]. These acetylated polyamines can form putrescine via oxidative deamination reactions catalyzed by polyamine oxidase (PAOX). Spermine oxidase (SMOX) catalyzes the oxidation of spermine to spermidine [1]. SSAT regulates the cellular polyamine content. SSAT is highly regulated according to changes in the polyamine content to maintain the steady state of polyamines. SSAT levels 
are usually very low but easily enhanced by increasing free polyamines. SSAT activity can also be induced by a variety of other stimuli, including toxins, hormones, cytokines, non-steroidal anti-inflammatory agents, natural products and stress, and ischemia-reperfusion injury [27]. SMOX and PAOX are likely to produce large amounts of reactive oxides (ROS), leading to oxidative damage [28].

\section{Polyamine transport system}

Polyamines are protonated at a physiological $\mathrm{pH}$, which hinders their passive transport through the plasma membrane. Instead, the active transportation of polyamines through the polyamine transport system has the characteristics of energy and temperature dependence and saturation at low concentrations [22]. At present, there are several theories regarding polyamine transport.

One theory suggests that heparan sulfate and glypican 1 (GPC1) coordinately transport spermine. Spermine interacts with the heparan sulfate group in GPC1 on the cell surface and enters into the cell. Spermine is then released through NO-mediated oxidation to act on cells [29].

Another view is that polyamine transport is mediated by endocytosis and solute carrier transport mechanisms. Polyamines bind to polyamine binding proteins and are internalized by endocytosis. Caveolin-1 knockout promotes endocytosis and increases the frequency or amount of polyamine internalization but does not change the affinity of the polyamine to bind to the cell surface [30]. According to this theory, SLC3A2 exports putrescine and acetylated polyamines via diamine/arginine exchange activity [31]. In the case of high extracellular putrescine and low intracellular putrescine, the concentration gradient can drive SLC3A2 to become a carrier of putrescine [30]. Subsequently, it was discovered that caveolin-1 negatively regulates polyamine uptake by inhibiting GST $\prod$ secretion by stimulating actin remodeling and endocytosis [32].

Alternatively, it is thought that polyamines are transported into cells through an unrecognized transporter driven by membrane potential. Polyamine penetrates the cell through the plasma membrane. The accumulated polyamines are subsequently localized in polyamine isolation vesicles, which relies on the vacuolar ATPase $\mathrm{pH}$ gradient and proton exchange, illustrating the two-step mechanism of polyamine transport and vesicle chelation [33].

Research on polyamine transporters has been progressing. There is evidence that Membrane transporters may mediate the transport of polyamines. For example, the transport proteins encoded by $S L C 22 A 1, S L C 3 A 2$,
SLC22A16, and SLC12A8A can transfer putrescine or spermidine and spermine into cells. $S L C 18 B 1$ is a recently identified gene in the family of vesicle amine transporters. This protein is responsible for the storage and release of polyamine vesicles and functions as a vesicle polyamine transporter [34].

Recent studies have shown that deficiency in ATP13A2, a late endolysosomal transport protein, can interfere with lysosomal polyamine transfer. ATP13A2 promotes the uptake of polyamines by cells through endocytosis and transports them to the cytoplasm, highlighting the role of endolysosomes in the uptake of polyamines into cells [35].

\section{Polyamines and cancers}

As mentioned earlier, polyamine dysregulation has been found in a variety of cancers. For example, polyamine metabolism plays a key role in cell death and proliferation in breast cancer. And there is evidence that polyamines facilitate the interactions of transcription factors, such as estrogen receptors and nuclear factor $\mathrm{kB}$, with their specific response element and are also involved in the proliferation of ER-negative and highly invasive models of tumor cells [11,36]. Polyamines are polycationic compounds that play a key role in almost all the steps of colorectal tumorigenesis. In the tissue of colorectal cancer, the polyamine content as well as the activities of two important enzymes in their biosynthesis such as ornithine decarboxylase and S-adenosylmethionine decarboxylase, are increased $3 \sim$ fourfold over that found in the equivalent normal colonic tissue. The researchers found that polyamines could be a target for chemoprevention. Therefore, it can be deduced that influencing polyamine metabolism by drugs and diet is able to reduce cancer risk $[14,37,38]$. The polyamine content in prostate cancer was significantly higher than that in benign prostatic hyperplasia. Prostate cancer cells maintain the secretion of polyamines while proliferating, so they need a high level of polyamine metabolic flux. Polyamine metabolic pathway may be a target of prostate cancers [12,38]. Some researchers have proved that polyamines play an important role in the early promotion stage of skin tumor by building transgenic mouse model. Polyamines can stimulate epidermal proliferation, change the differentiation of keratinocytes, increase neovascularization, and increase the synthesis of proteins in extracellular matrix in a manner similar to wound healing. The increase of polyamine level can not only activate epidermal cells, but also subcutaneous stromal cells, thus promoting the development and progression of skin tumors. Targeted 
ornithine decarboxylase has been shown to prevent non-melanoma skin cancer in human $[10,13]$.

Therefore, polyamines and their metabolites are often regarded as cancer biomarkers. In recent years, metabonomics technology can more sensitively observe the changes of polyamine synthesis and metabolism in cancer. Polyamines and their metabolites in urine and plasma can be used as biomarkers of occurrence and progression in a variety of tumors, such as breast cancer, lung cancer, colorectal cancer, ovarian cancer, prostate cancer and pancreatic cancer [22]. In addition, it has been observed that polyamines improve the malignancy of tumors and the invasion and metastasis of cancer cells, and reduce the anti-tumor immune function of immune cells [39, 40].

\section{Polyamine-associated oncogenes and related signaling pathways}

The mechanism by which polyamines affect the occurrence and development of cancer has been the focus of many researchers. This review summarizes the oncogenes that interact with polyamine pathway, as shown in Table 1.

\section{MYC}

The $M Y C$ transcription factor family is one of the central and most studied groups in cancer. In 1992, the Cleveland team first reported that c-myc could regulate ODC expression at the transcription level [41]. The ODC1 gene contains a $M Y C$ binding site in its promoter, which contains a conserved E-box motif. A single nucleotide polymorphism in the E-box region of the $O D C 1$ gene affects the binding of $M Y C$ and $M A D$ to $O D C 1$ and is related to the recurrence of colon cancer [42].

There are frequent mutations of one or more $M Y C$ genes in various cancers, and the overexpression of $O D C 1$ is regulated by $M Y C$ activation. For example, in neuroblastoma, bioinformatics analysis of a large number of human neuroblastoma samples showed that genes associated with polyamine biosynthesis, including $O D C 1$, AMD1, ARG1, AZIN1, DHPS, EIF5A, MAT1B, SMS, $S M O X$, and $S R M$, were upregulated in $M Y C N$-amplified/ upregulated neuroblastoma. In contrast, $O A Z 2, P A O X$, and $S A T 1$ genes involved in polyamine catabolism were downregulated in tumors. $M Y C N$ also regulated the key polyamine transport protein SLC3A2, and their expression levels were positively correlated [43-46]. A recent study had demonstrated that downregulation of both SMS and MYC synergistically induces apoptin Bim expression in colorectal cancer cells, indicating that combined inhibition of SMS and MYC signaling may be an effective therapy for colorectal cancer [47].
Other studies found that polyamine negative feedback regulates the expression of $M Y C$. For example, it has been demonstrated that putrescine triggers the transcription of c-myc mRNA in renal cells of Kirsten sarcoma virus-infected rats, while difluoromethylornithine (DFMO) inhibits ODC activity and blocks the transcription of c-myc [48]. Polyamines in rat intestinal epithelial cells enhance the association between $\mathrm{HuR}$ and the $3^{\prime}$-untranslated region of c-myc mRNA by increasing the HuR-mediated phosphorylation of CHK2, thereby promoting c-myc translation [49]. In addition, polyamines drive the expression of c-myc by inducing the fourchain structure of c-myc to form a transcriptionally active motif with unique molecular recognition properties [50].

\section{p53}

The combination of p53 with CPS, OTC, and ARG, the key enzymes of the urea cycle, downregulates the transcription of these enzymes. It inhibits urea production and ammonia elimination in vitro and in vivo, thereby inhibiting tumor growth. In contrast, the downregulation of these genes activates p53 through a mechanism mediated by MDM2.The accumulation of ammonia leads to a significant decrease in the mRNA translation of the polyamine biosynthesis rate-limiting enzyme ODC, which inhibits polyamine biosynthesis and cell proliferation. However, ammonia does not affect the ubiquitination state of ODC proteins or the interaction between ODC monomers. Similarly, p53 deletion increases the overall level of ODC monomers and dimers, and thus p53 regulates ammonia metabolism through the urea cycle to control polyamine biosynthesis [51].

There are two 553 binding sites in the promoter region of $S A T 1$, indicating that the $S A T 1$ gene is a transcriptional target of p53. P53 mediates the activation of SAT1 expression, which induces lipid peroxidation and causes iron death under ROS-induced stress [52].

It has been found that spermine can induce autophagy, which is related to the activation of p53 transcription [53]. AdoMetDC is an essential enzyme for polyamine biosynthesis. Its inhibitor SAM486A leads to the rapid accumulation of the pro-apoptotic proteins p53 and MDM2 [54]. The inhibition of ODC increases the phosphorylation of p53 and MDM2, and the resistance to apoptosis [55]. Polyamines play an important role in maintaining the integrity of the normal intestinal epithelium. The depletion of polyamines can significantly enhance the cytoplasmic abundance of $\mathrm{HuR}$, which specifically binds to the untranslated region of p53 mRNA. Therefore, polyamines can 


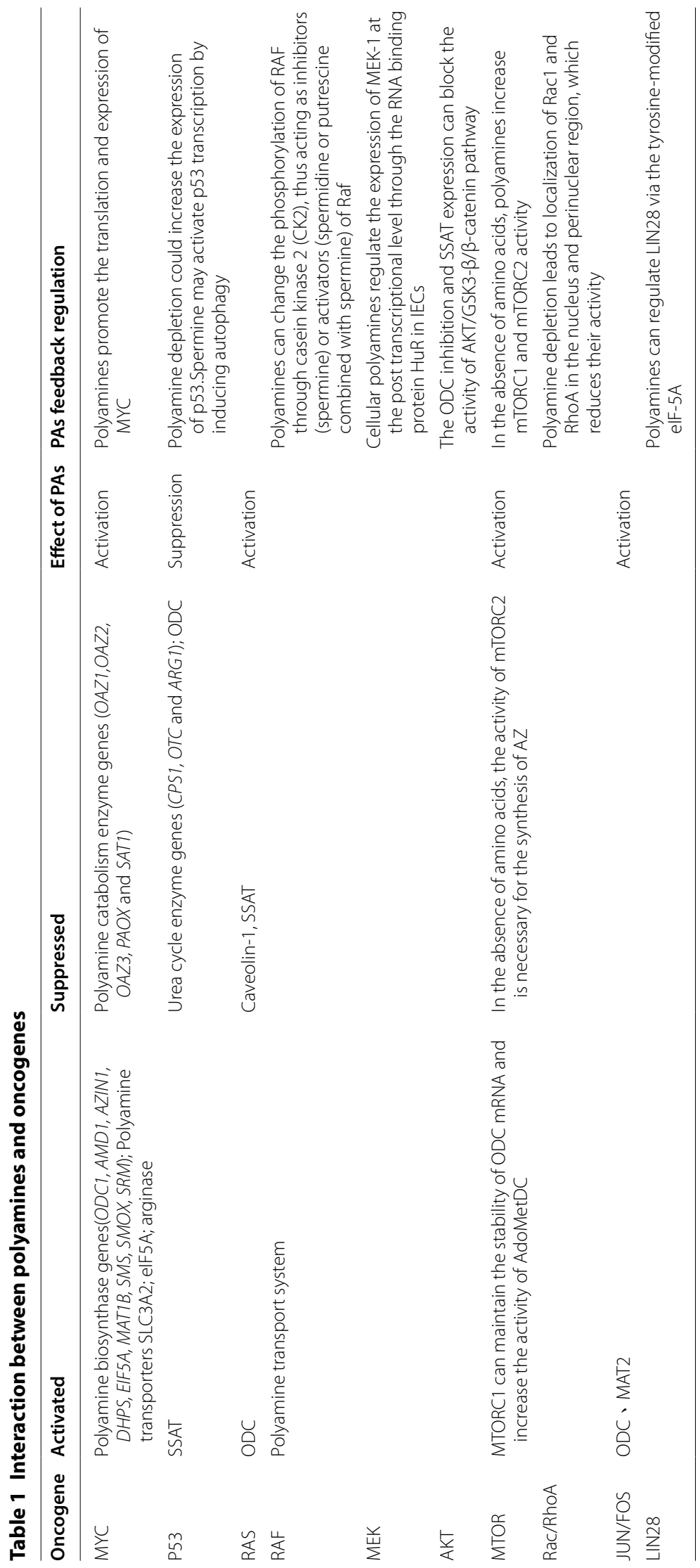


control the stability of p53 mRNA and affect the level of p53 protein [56].

\section{RAS/RAF/MEK pathway RAS}

The transcription and translation of ODC is controlled by RAF/MEK/ERK pathways [57]. Ras activation enhances IRES-mediated ODC translation activity independent of cap. This regulation is dependent on the phosphorylation state of eIF4E. Dephosphorylation of eIF4E by inhibition of MEK or MNK1/2 inhibitor the activity of ODC-IRES [58].

The activated $K-R A S$ significantly increases the uptake of polyamines by colon cancer cells. Activated K-RAS changes the subcellular distribution of the UPAR ligand uPA, which activates Src. Activation of Src increases the phosphorylation of caveolin-1, which is a negative regulator of caveolin-1 endocytosis [59].

It has been shown that $K-R A S$ mutations can inhibit SSAT expression through the peroxisome proliferator activated receptor- $\gamma$ (PPAR $\gamma$ ) response element, which is located at +48 bp relative to the transcription start site of the SSAT, to maintain a high level of polyamine in transformed cells [17].

In $H-R A S$ transformed cells, the regulation of multiple cytokines could affect the expression of key enzymes in polyamine anabolism. For example, ODC is regulated by basic fibroblast growth factor (bFGF), transforming growth factor $\beta$ (TGF- $\beta$ ), platelet-derived growth factor (PDGF), and cAMP [60-63]. Similarly, S-adenosylmethionine decarboxylase expression is regulated by epidermal growth factor (EGF) and bFGF [64].

\section{RAF}

Missense mutations in the $B R A F$ oncogene occur in more than $50 \%$ of malignant melanomas [65]. BRAF inhibitors against $B R A F$-mutated tumors are susceptible to drug resistance [66]. An in vitro study demonstrated that compared with wild-type $B R A F$ melanoma cells, mutant $B R A F$ melanoma cells showed stronger PTS activity and were more sensitive to PTS-targeted cytotoxic drugs [67].

Polyamines can change the phosphorylation of Raf through casein kinase 2, thus acting as inhibitors (spermine) or activators (spermidine or putrescine combined with spermine) of Raf [5]. Some experiments indicate that under the condition of satisfying the selective susceptibility, an increase in ODC results in an increase in polyamines, which in combination with the activation of the RAF/MAPK pathway, can transform normal keratinocytes into invasive malignant cells [68].

\section{MEK}

MEK-1 is a key effector in HuR-induced anti-apoptotic programs in intestinal epithelial cells (IECs). Cellular polyamines regulate the expression of MEK- 1 at the posttranscriptional level through the RNA binding protein HuR in IECs. MEK-1 mRNA can be stabilized by inhibiting the decrease in cell polyamine levels caused by ODC, and its translation can be promoted by enhancing the interaction between $\mathrm{HuR}$ and the $3^{\prime}$-untranslated region of MEK-1 mRNA [69].

\section{AKT}

AKT is involved in several cell processes, such as cell survival, growth, and migration. It is known that the inhibition of ODC expression can block the activation of the AKT pathway in acidosis microenvironments. ODC is co-expressed with $\beta$-catenin in liver cancer. The expression and nuclear localization of $\beta$-catenin decreases after ODC inhibition. Blocking the metabolism of polyamines by treatment with polyamine conjugates inhibits the activity of AKT and apoptosis-related proteins [70].

In addition, high levels of polyamines activate AKT. According to previous reports, exogenous polyamines can induce cancer cell proliferation and migration through AKT-mediated pathways [71]. Polyamines regulate hypoxia-induced apoptosis of endothelial cells through the PI3K/AKT pathway, which is of great significance to the regulation of hypoxia driven neovascularization [72]. It has also been shown in several human hepatocarcinoma and colon cancer cell models that SSAT expression mediated polyamine depletion can significantly inhibit the expression of p-Akt, p-GSK3 $\beta$, and $\beta$-catenin nuclear translocation, thus inhibiting the growth, migration, and invasion of cancer cells [73].

\section{mTOR}

mTOR forms two different complexes named mTOR complex 1 (mTORC1) and complex 2 (mTORC2). Polyamines are necessary for the synthesis of AZ. In the absence of amino acids, the activity of mTORC2 is necessary for the synthesis of AZ. Because mTORC1 is inhibited, and mTORC2 is activated, the synthesis of total protein is inhibited, and the synthesis of AZ1 is increased through a cap-independent mechanism. In addition, it was subsequently demonstrated that putrescine, spermidine, and spermine all increased mTORC2 activity, whereas spermidine and spermine increased mTORC1 activity $[74,75]$. mTORC1 inhibition reduces the association of the mRNA binding protein HuR with ODC transcripts, thereby destabilizing ODC mRNA [76]. In glioma cells, the activation of polyamine catabolism alters the location of mTOR, negatively affecting mTOR-mediated 
protein synthesis and leading to apoptosis [77]. It has been shown that spermidine can reduce apoptosis by promoting AMPK/mTOR-mediated autophagy flux [78].

Using comprehensive metabolomics methods in mouse and human prostate tumors, it was found that the protein level of AdoMetDC is increased in PTEN-deficient prostate cancer cells. PTEN is a tumor suppressor that is frequently mutated or lost in prostate cancer. Loss of PTEN function causes an abnormal response to growth factor (GF) stimulation through the PI3K signaling pathway, thereby activating mTORC1. mTORC1 inhibitors induce AdoMetDC downregulation, and at the same time, $\mathrm{dcSAM}$ production and polyamine synthesis are reduced. Mechanistically, activated mTORC1 indirectly blocks the proteasome degradation of pro-AdoMetDC and leads to phosphorylation at the S298 site, further stabilizing it. Then, the proenzyme self-processes into an active holoenzyme containing pyruvate, promoting an increase in the production of polyamines necessary for neoplastic growth [79].

\section{Others}

\section{Rac and RhoA}

Studies have shown that inhibition of RhoA activity and depletion of polyamines inhibit cell migration, causing changes in the actin cytoskeleton. Polyamine depletion leads to Rac1 and RhoA localization in the nucleus and perinuclear region, which reduces the levels of Rac1 and RhoA protein in the cytoplasm and at the plasma membrane, significantly reducing their activity. These findings provide novel insights into the mechanisms by which ODC and polyamines regulate cytoskeletal dynamics during cell proliferation and transformation [80-82].

Polyamines increase intracellular free $\mathrm{Ca}^{2+}$ concentrations by controlling voltage-gated $\mathrm{K}+$ channel expression and membrane potential $(\mathrm{E}(\mathrm{m})$ ) during intestinal epithelial repair. This increases the binding of GTP to RhoA, which can interact with and activate Rho kinase during intestinal epithelial repair [83].

\section{JUN and FOS}

It has been reported that Helicobacter pylori activate polyamine-dependent mechanisms through specific MAPK pathways to induce macrophage apoptosis. H. pylori activate ERK, and the translocation of $\mathrm{p}$-ERK to the nucleus can lead to activation of activator protein 1 (AP-1). AP-1 consists of a phosphorylated c-Fos/c-Jun heterodimer that binds to the c-myc promoter in macrophages, thereby inducing the expression of c-myc and ODC and increasing polyamine production. Subsequently, the oxidation of spermine by spermine oxidase to produce hydrogen peroxide causes mitochondrial membrane polarization, which eventually leads to cell apoptosis [84,
85]. Similarly, in colon cancer, the expression of ODC, MAT2, FOS, and JUN in tumor tissues is higher than that in adjacent normal mucosa to provide polyamines for tumor cell proliferation [86].

\section{LIN28/let-7 pathway}

The Lin28/let-7 pathway is involved in the metabolism of polyamines and plays a key role in the regulation of normal and cancer stem cell self-renewal. Lin28 and Wnt signaling pathways cooperate to promote the development of invasive intestinal and colon cancers [87]. The let-7 family is negatively regulated by the pluripotent factor Lin28. Polyamines can regulate LIN28 via the tyrosine-modified eukaryotic translation initiation factor $5 \mathrm{~A}$ (eIF-5A), which uses spermidine as substrate, thus affecting specific aspects of tumorigenesis [88].

\section{Hedgehog pathway}

In Hedgehog pathway, signal transmission is controlled by patched $(\mathrm{PTCH})$ and smoothed (SMO) receptors on the target cell membrane. At the post-receptor level, cytoplasmic regulators suppressor of fused (SUFU) and glioma-associated oncogene transcription factors are key mediators of the Hedgehog transcription [89]. In medulloblastoma, tumors in the sonic hedgehog subgroup show abnormal activation of Hedgehog signaling. SMO activation triggers the non-classical hedgehog signaling pathway associated with the energy sensor AMPK. Cell nucleic acid-binding protein (CNBP), a type of RNA binding protein, is the key factor for this reaction. Through phosphorylation modifications, CNBP increases its stability and close interactions with SUFU. The SUFUCNBP complex binds to the $5^{\prime}$ untranslated region of ODC mRNA and promotes its translation, thereby increasing polyamine metabolism [90].

\section{DFMO in polyamine chemoprevention}

Inhibition of ODC activity and polyamine synthesis is theoretically beneficial to cancer prevention. Based on preclinical and early clinical studies, DFMO is expected to be a promising chemical prophylactic. Some clinical trials have studied the chemopreventive effect of the polyamine inhibitor DFMO on cancer.

This review used keywords to search the literature from several English databases (Pubmed, Embase, Cochrane library, Scopus, Web of Science) and selected the collected literature through the following inclusion criteria: (1) clinical randomized controlled trials, (2) studies set up groups that used and did not use DFMO, (3) the participants in the trial were treated cancer patients or high-risk groups prone to cancer, and (4) observation indicators related to the outcome may indicate remission or deterioration of the patient's 


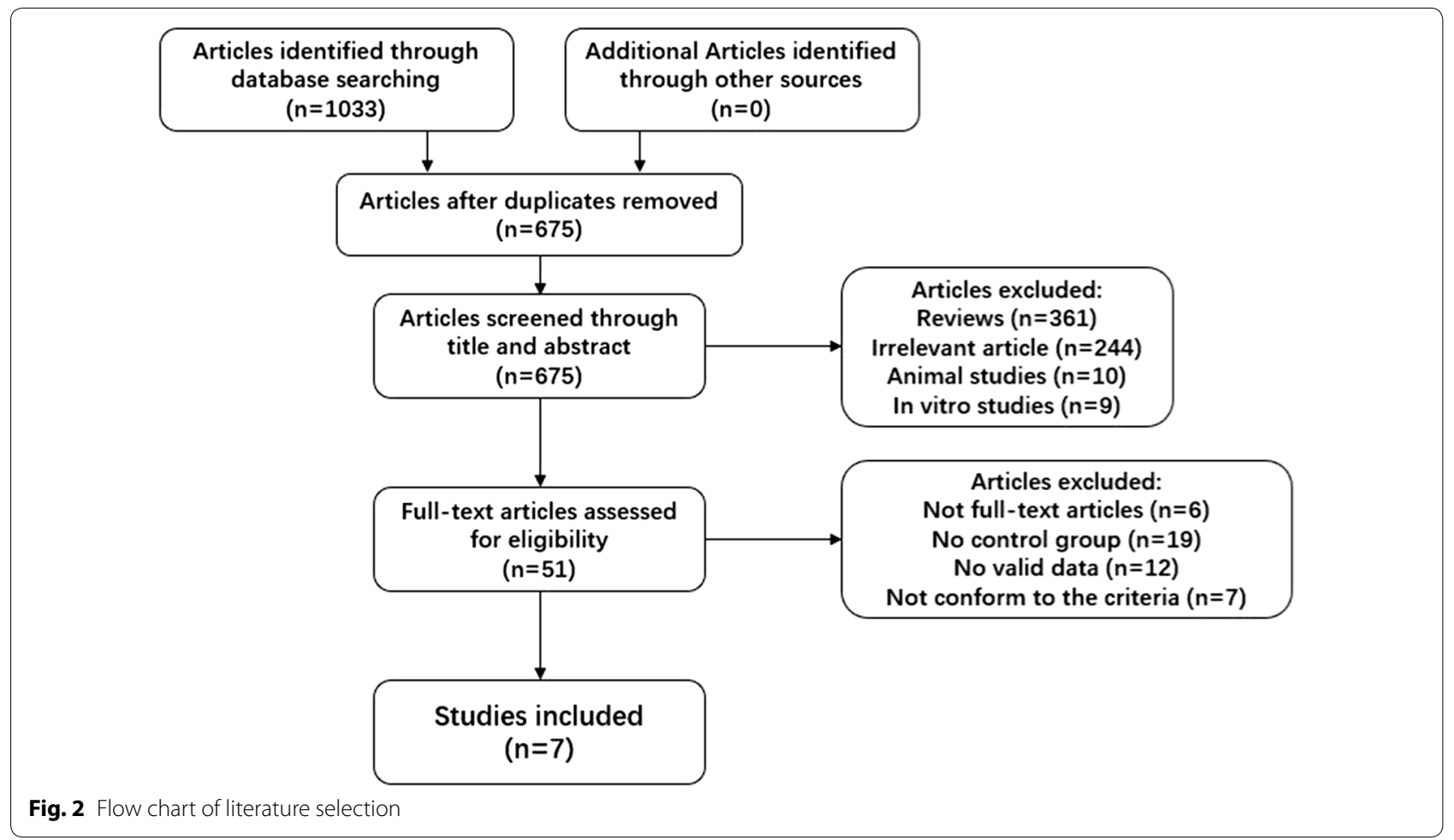

condition. The literature screening process is shown in Fig. 2. In this process, two researchers screened the literature back-to-back at the same time, and after two checks, the results were confirmed to be consistent, the following documents were finally included. The details of the final included literature are shown in Table 2.

Some researchers have applied DFMO to cancer patients who have regained function after treatment. Recently, a study had demonstrated the evaluation of DFMO as a maintenance treatment regimen for highrisk neuroblastoma. The results showed that the survival status of subjects receiving DFMO for 2 years was maintained well. Therefore, further research on this drug as a maintenance therapy is warranted [91]. It has been evaluated the ability of DFMO to prevent the recurrence of low-risk superficial bladder cancer. The results showed that the tumor recurrence could not be delayed or prevented in low-grade (Grade 1 and 2), superficial (Ta or T1), newly diagnosed or occasionally recurrent bladder urothelial cancer, by using one-year DFMO after the operation of complete resection [92]. 211 participants with a history of non-melanoma skin cancer were randomly assigned to oral DFMO $(500 \mathrm{mg} /$ $\mathrm{m}^{2} /$ day) or placebo for $4-5$ years. The primary endpoint was the production of new Non-melanoma skin cancer, with fewer new cancers in the DFMO group than in the placebo group, but there was no statistical difference [93].
Others have used DFMO to treat high-risk groups prone to cancer. For example, a study of familial adenomatous polyposis (FAP) showed moderate synergistic effects of DFMO in combination with celecoxib compared with the use of the non-steroidal anti-inflammatory drug celecoxib alone [94]. In a double-blind randomized trial, DFMO $\left(0.125,0.5 \mathrm{gm} / \mathrm{m}^{2}\right)$ and placebo were used to treat cervical intraepithelial neoplasia (CIN) grade $2-3$ patients. There was no significant difference in histopathological responses among the groups [95].

For actinic keratosis (AK), a precancerous lesion that is easy to develop into skin cancer, preclinical studies have shown that the level of skin polyamine is related to the use of DFMO [96], in individuals with signs of actinic keratosis, but the impact of DFMO on the disease is still controversial in clinical trials. It has shown that the combination of DFMO and other drugs can not enhance the activity of treating skin sunburn. The reason may be that the baseline population has mild sun damage [97, 98].

\section{Conclusions}

Over the past decades, polyamine research has continuously progressed. We now have a better understanding of the anabolic pathways and transport processes of polyamines. Moreover, the effects of polyamines on cancer cells have also been explored. This review describes polyamine-related oncogenes and the signaling pathways involved. We found that oncogenes can affect the 


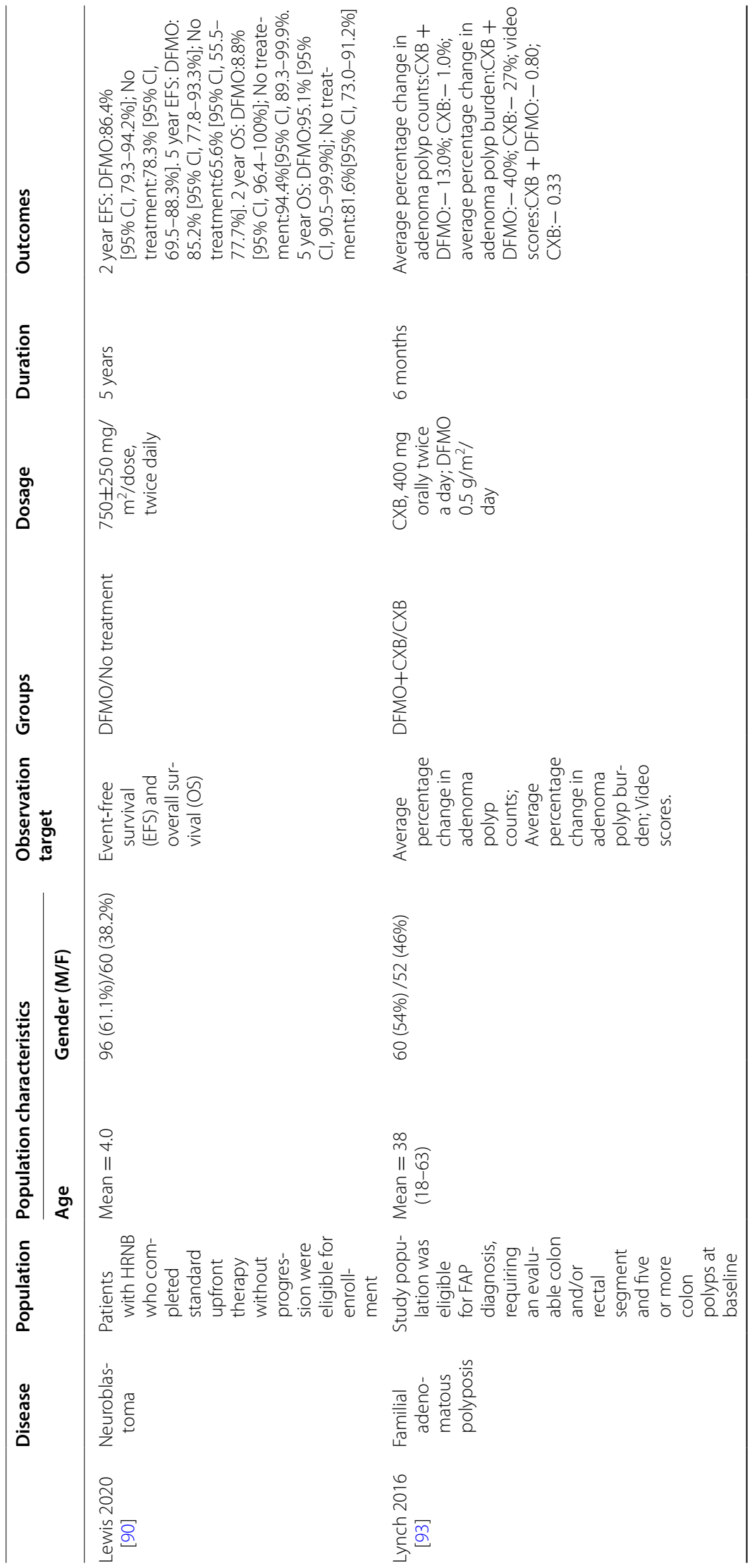




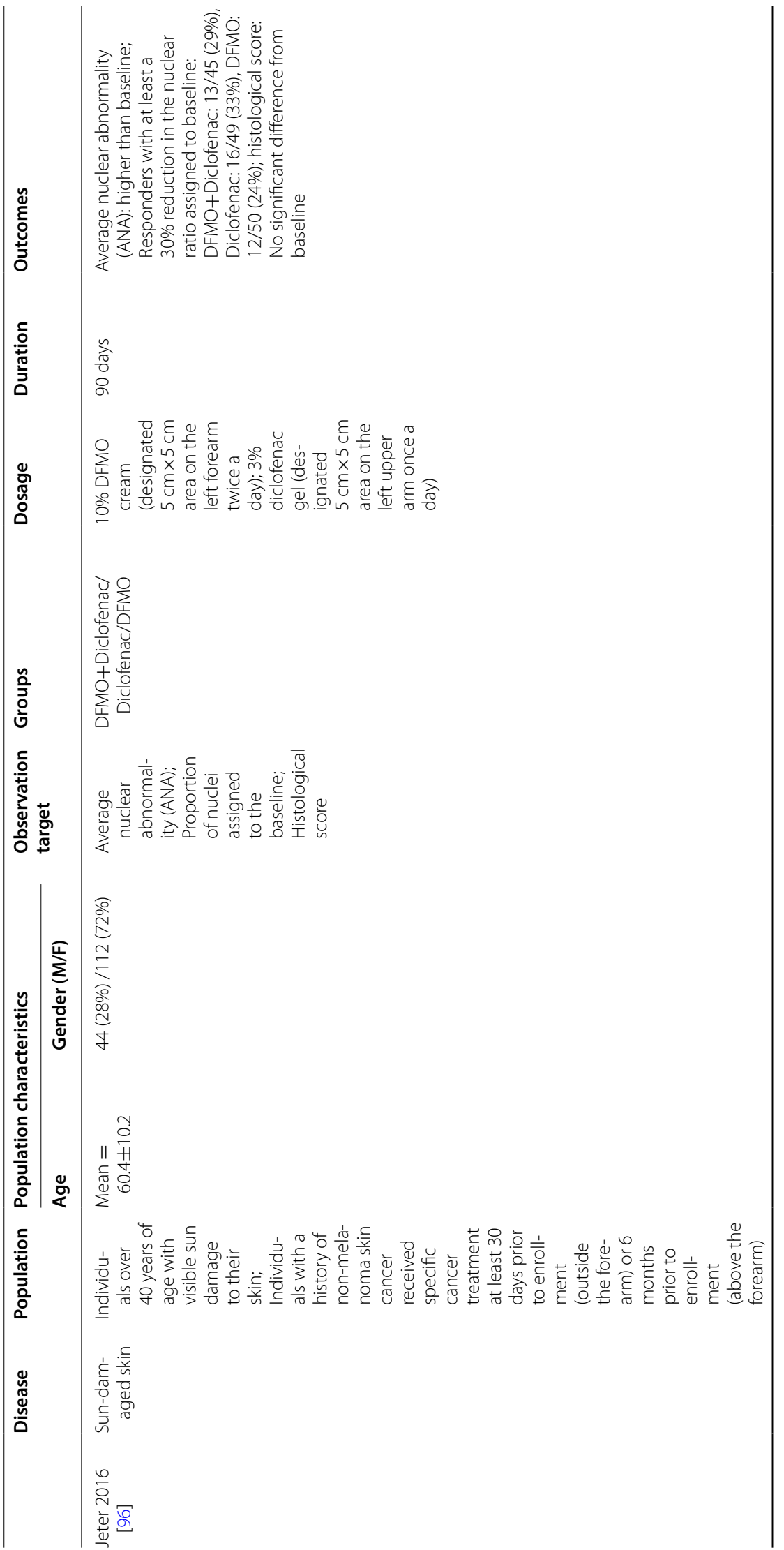




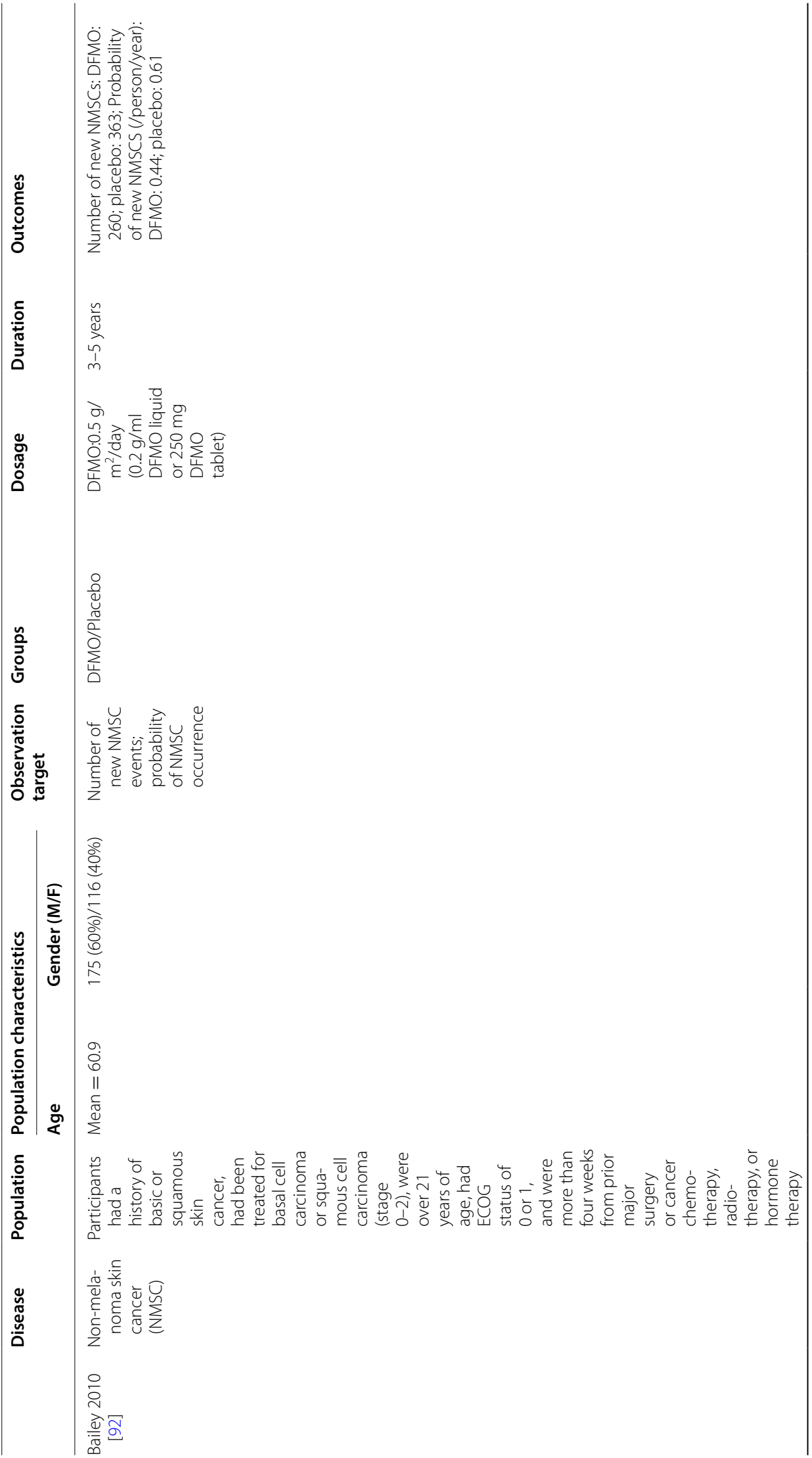




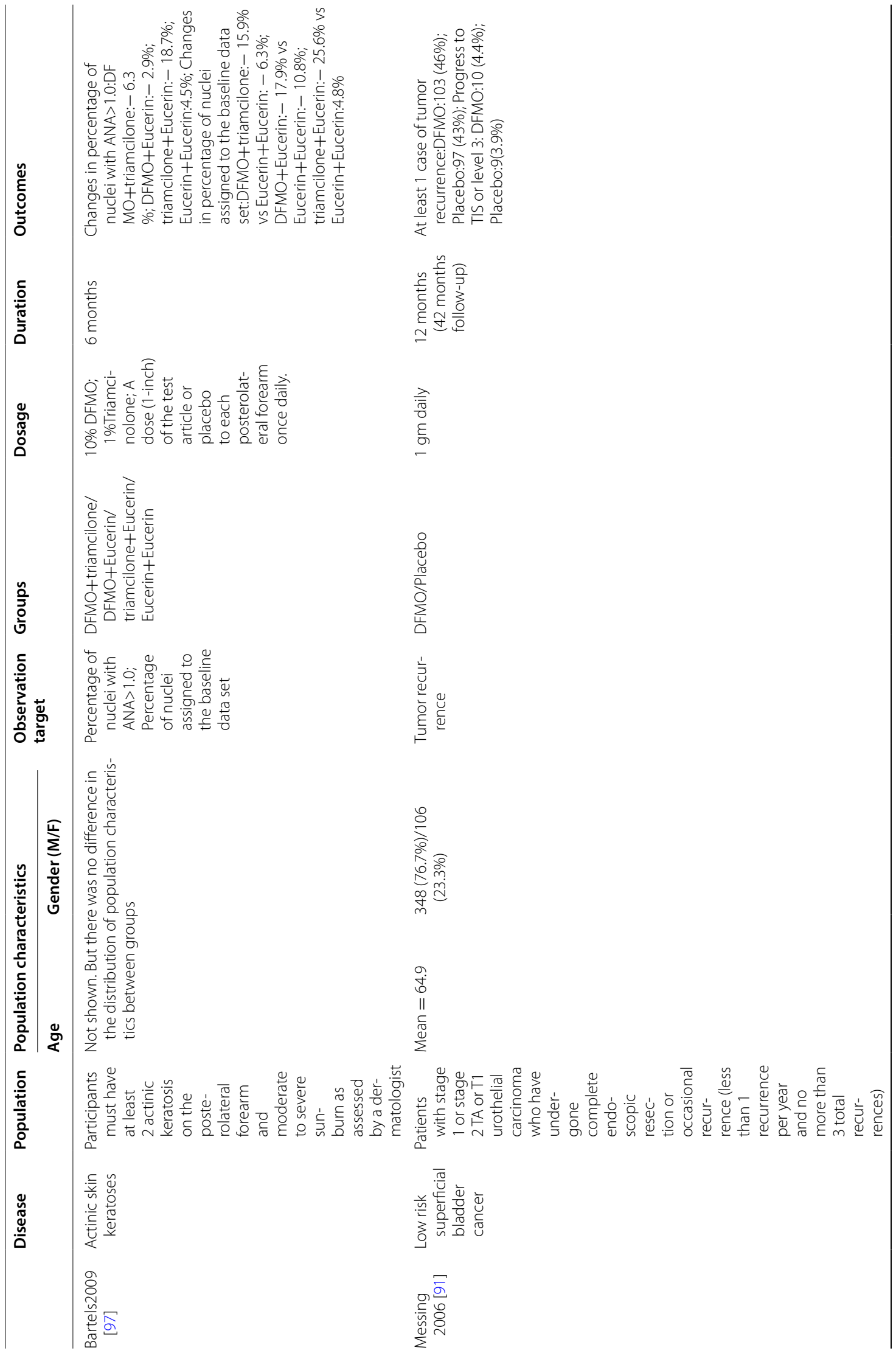




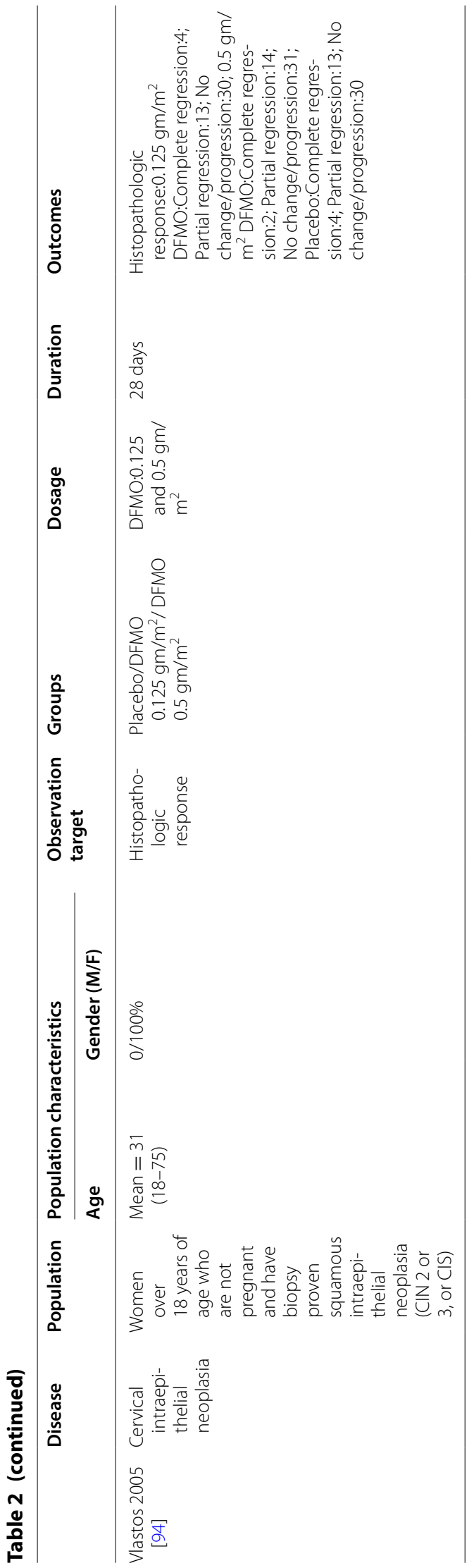


metabolism and function of polyamines by interfering with the translation and expression of key enzymes. Polyamines can also affect the expression of oncogenes in various ways, thus regulating the physiological function of cancer cells. However, the mechanism of polyamine effect on cancer needs further study, and the types of cancer that have been studied on polyamine metabolism are limited. But the existing research has provided us with new ideas for the treatment of cancer. In fact, some enzyme inhibitors and polyamine analogs have been used as drug interventions in clinical trials and achieved some promising results. This review summarizes the current research on DFMO, a promising drug for cancer chemoprevention. We found that DFMO could slow down the development of cancer in high-risk groups. Nevertheless, DFMO has no significant effect on preventing cancer recurrence for people who have received cancer treatment and recovered their functions, but it is beneficial to maintain their survival status. In summary, we need to further explore the role of polyamines in tumor cells and develop new interventions for cancer treatment and chemoprevention. It is also important to combine drugs targeting the polyamine pathway with other therapies to achieve better outcomes than monotherapies.

\begin{abstract}
Abbreviations
ODC: Ornithine decarboxylase; AdoMetDC: S-adenosine methionine decarboxylase; MTA: 5'-Methyl thio-adenosine; AGMAT: Agmatinase; AZ: Anti enzyme; AZI: Antizyme inhibitor; SSAT: Spermidine/spermine-N-acetyltransferase; PAOX: Polyamine oxidase; SMOX: Spermine oxidase; ROS: Reactive oxides; PTS: Polyamine transport system; GPC1: Glypican 1; DFMO: Difluoromethylornithine; UPAR: Urokinase plasminogen activated receptor; PPARY: Peroxisome proliferator activated receptor- $\gamma$; bFGF: Basic fibroblast growth factor; TGF- $\beta$ : Transforming growth factor $\beta$; PDGF: Platelet-derived growth factor; EGF: Epidermal growth factor; IECs: Intestinal epithelial cells; mTORC1: MTOR complex 1; mTORC2: MTOR complex 2; AP-1: Activator protein 1; elF-5A: Eukaryotic translation initiation factor 5A; PTCH: Patched; SMO: Smoothed; SUFU: Suppressor of fused; CNBP: Cell nucleic acid-binding protein; FAP: Familial adenomatous polyposis; ER: Estrogen receptor; CIN: Cervical intraepithelial neoplasia; AK: Actinic keratosis; AMPK: Adenosine monophosphate activated protein kinase.
\end{abstract}

\section{Acknowledgements}

Not applicable

\section{Authors' contributions}

$J \mathrm{~L}$ drafted the manuscript. XW assisted $\mathrm{JL}$ in screening articles. $J \mathrm{~L}, \mathrm{YS}$ and $\mathrm{YM}$ discussed and revised the manuscript. All authors read and approved the final manuscript.

\section{Funding}

The Science and Technology Natural Science Foundation of Jilin Provincial, Grant/Award Number: 20200201125JC; The National Natural Science Foundation of China, Grant/Award Number: 81370240; The Health Technology Innovation Project of Jilin Province, Grant/Award Number: 2017J059.

\section{Availability of data and materials}

Not applicable.

Ethics approval and consent to participate

Not applicable.
Consent for publication

Not applicable.

\section{Competing interests}

The authors declare that they have no competing interests.

\section{Author details}

1 Department of Otorhinolaryngology-Head and Neck Surgery, China-Japan Union Hospital, Jilin University, Changchun, Jilin Province, China. ${ }^{2}$ Department of Pathophysiology, Prostate Diseases Prevention and Treatment Research Center, College of Basic Medical Science, Jilin University, Changchun, China.

Received: 1 July 2020 Accepted: 8 September 2020

Published online: 05 November 2020

\section{References}

1. Casero RA, Pegg AE. Polyamine catabolism and disease. Biochem J. 2009:421(3):323-38.

2. Choi YH, Park HY. Anti-inflammatory effects of spermidine in lipopolysaccharide-stimulated BV2 microglial cells. J Biomed Sci. 2012;19(1):31.

3. Pirinen E, Kuulasmaa T, Pietilä M, Heikkinen S, Tusa M, Itkonen P, et al. Enhanced polyamine catabolism alters homeostatic control of white adipose tissue mass, energy expenditure, and glucose metabolism. Mol Cell Biol. 2007;27(13):4953-67.

4. Yuan Q, Ray RM, Viar MJ, Johnson LR. Polyamine regulation of ornithine decarboxylase and its antizyme in intestinal epithelial cells. Am J Physiol Gastrointest Liver Physiol. 2001;280(1):G130-8.

5. Minois N. Molecular basis of the "anti-aging" effect of spermidine and other natural polyamines - a mini-review. Gerontology. 2014;60(4):319-26.

6. Igarashi K, Kashiwagi K. Modulation of cellular function by polyamines. Int J Biochem Cell Biol. 2010;42(1):39-51.

7. Moinard C, Cynober L, de Bandt JP. Polyamines: metabolism and implications in human diseases. Clin Nutr . 2005;24(2):184-97.

8. Casero RA Jr, Marton LJ. Targeting polyamine metabolism and function in cancer and other hyperproliferative diseases. Nat Rev Drug Discov . 2007:6(5):373-90.

9. Murray-Stewart TR, Woster PM, Casero RA Jr. Targeting polyamine metabolism for cancer therapy and prevention. Biochem J. 2016:473(19):2937-53.

10. Elmets CA, Athar M. Targeting ornithine decarboxylase for the prevention of nonmelanoma skin cancer in humans. Cancer Prev Res (Phila). 2010;3(1):8-11.

11. Manni A, Grove R, Kunselman S, Aldaz CM. Involvement of the polyamine pathway in breast cancer progression. Cancer Lett. 1995;92(1):49-57.

12. Gupta S, Ahmad N, Marengo SR, MacLennan GT, Greenberg NM, Mukhtar $\mathrm{H}$. Chemoprevention of prostate carcinogenesis by alpha-difluoromethylornithine in TRAMP mice. Can Res. 2000;60(18):5125-33.

13. Gilmour SK. Polyamines and nonmelanoma skin cancer. Toxicol Appl Pharmacol. 2007;224(3):249-56.

14. Upp JR Jr, Saydjari R, Townsend CM Jr, Singh P, Barranco SC, Thompson JC. Polyamine levels and gastrin receptors in colon cancers. Ann Surg. 1988;207(6):662-9.

15. Shantz LM, Levin VA. Regulation of ornithine decarboxylase during oncogenic transformation: mechanisms and therapeutic potential. Amino Acids. 2007;33(2):213-23.

16. Tobias KE, Shor J, Kahana C. C-Myc and Max transregulate the mouse ornithine decarboxylase promoter through interaction with two downstream CACGTG motifs. Oncogene. 1995;11(9):1721-7.

17. Ignatenko NA, Babbar N, Mehta D, Casero RA Jr, Gerner EW. Suppression of polyamine catabolism by activated Ki-ras in human colon cancer cells. Mol Carcinog. 2004;39(2):91-102.

18. Poulin R, Casero RA, Soulet D. Recent advances in the molecular biology of metazoan polyamine transport. Amino Acids. 2012;42(2-3):711-23.

19. Pegg AE. Regulation of ornithine decarboxylase. J Biol Chem 2006;281(21):14529-32.

20. Ikeguchi Y, Bewley MC, Pegg AE. Aminopropyltransferases: function, structure and genetics. J Biochem. 2006;139(1):1-9. 
21. Pegg AE. S-Adenosylmethionine decarboxylase. Essays Biochem. 2009;46:25-45.

22. Casero RA Jr, Murray Stewart T, Pegg AE. Polyamine metabolism and cancer: treatments, challenges and opportunities. Nat Rev Cancer. 2018;18(11):681-95.

23. Wang X, Ying W, Dunlap KA, Lin G, Satterfield MC, Burghardt RC, et al. Arginine decarboxylase and agmatinase: an alternative pathway for de novo biosynthesis of polyamines for development of mammalian conceptuses. Biol Reprod. 2014;90(4):84.

24. Wu HY, Chen SF, Hsieh JY, Chou F, Wang YH, Lin WT, et al. Structural basis of antizyme-mediated regulation of polyamine homeostasis. Proc Natl Acad Sci USA. 2015;112(36):11229-34.

25. Kahana C. The antizyme family for regulating polyamines. J Biol Chem. 2018;293(48):18730-5.

26. Bae DH, Lane DJR, Jansson PJ, Richardson DR. The old and new biochemistry of polyamines. Biochim Biophys Acta. 2018;1862(9):2053-68.

27. Pegg AE. Spermidine/spermine-N(1)-acetyltransferase: a key metabolic regulator. Am J Physiol Endocrinol Metab. 2008;294(6):E995-1010.

28. Pegg AE. Toxicity of polyamines and their metabolic products. Chem Res Toxicol. 2013;26(12):1782-800.

29. Belting M, Mani K, Jönsson M, Cheng F, Sandgren S, Jonsson S, et al. Glypican-1 is a vehicle for polyamine uptake in mammalian cells: a pivital role for nitrosothiol-derived nitric oxide. J Biol Chem. 2003;278(47):47181-9.

30. Uemura T, Stringer DE, Blohm-Mangone KA, Gerner EW. Polyamine transport is mediated by both endocytic and solute carrier transport mechanisms in the gastrointestinal tract. Am J Physiol Gastrointest Liver Physiol. 2010;299(2):G517-22.

31. Uemura T, Yerushalmi HF, Tsaprailis G, Stringer DE, Pastorian KE, Hawel $L$ 3rd, et al. Identification and characterization of a diamine exporter in colon epithelial cells. J Biol Chem. 2008;283(39):26428-35.

32. Uemura T, Tsaprailis G, Gerner EW. GSTП stimulates caveolin1-regulated polyamine uptake via actin remodeling. Oncotarget. 2019;10(55):5713-23.

33. Soulet D, Gagnon B, Rivest S, Audette M, Poulin R. A fluorescent probe of polyamine transport accumulates into intracellular acidic vesicles via a two-step mechanism. J Biol Chem. 2004;279(47):49355-66.

34. Moriyama Y, Hatano R, Moriyama S, Uehara S. Vesicular polyamine transporter as a novel player in amine-mediated chemical transmission. Biochim Biophys Acta Biomembr. 2020. https://doi.org/10.1016/j.bbame m.2020.183208

35. van Veen S, Martin S, Van den Haute C, Benoy V, Lyons J, Vanhoutte R, et al. ATP13A2 deficiency disrupts lysosomal polyamine export. Nature. 2020;578(7795):419-24.

36. Cervelli M, Pietropaoli S, Signore F, Amendola R, Mariottini P. Polyamines metabolism and breast cancer: state of the art and perspectives. Breast Cancer Res Treat. 2014;148(2):233-48.

37. Linsalata M, Orlando A, Russo F. Pharmacological and dietary agents for colorectal cancer chemoprevention: effects on polyamine metabolism (review). Int J Oncol. 2014;45(5):1802-12.

38. Affronti HC, Rowsam AM, Pellerite AJ, Rosario SR, Long MD, Jacobi JJ, et al. Pharmacological polyamine catabolism upregulation with methionine salvage pathway inhibition as an effective prostate cancer therapy. Nat Commun . 2020;11(1):52.

39. Soda K. The mechanisms by which polyamines accelerate tumor spread. J Exp Clin Cancer Res. 2011;30(1):95

40. Alexander ET, Minton A, Peters MC, Phanstiel Ot, Gilmour SK. A novel polyamine blockade therapy activates an anti-tumor immune response. Oncotarget. 2017;8(48):84140-52.

41. Bello-Fernandez C, Packham G, Cleveland JL. The ornithine decarboxylase gene is a transcriptional target of c-Myc. Proc Natl Acad Sci USA. 1993;90(16):7804-8.

42. Zell JA, Ziogas A, Ignatenko N, Honda J, Qu N, Bobbs AS, et al. Associations of a polymorphism in the ornithine decarboxylase gene with colorectal cancer survival. Clin Cancer Res. 2009;15(19):6208-16.

43. Bachmann AS, Geerts D. Polyamine synthesis as a target of MYC oncogenes. J Biol Chem. 2018;293(48):18757-69.

44. Gamble LD, Purgato S, Murray J, Xiao L, Yu DMT, Hanssen KM, et al. Inhibition of polyamine synthesis and uptake reduces tumor progression and prolongs survival in mouse models of neuroblastoma. Sci Transl Med. 2019. https://doi.org/10.1126/scitranslmed.aau1099.
45. Hackett CS, Quigley DA, Wong RA, Chen J, Cheng C, Song YK, et al. Expression quantitative trait loci and receptor pharmacology implicate Arg1 and the GABA-A receptor as therapeutic targets in neuroblastoma. Cell Rep . 2014;9(3):1034-46.

46. Mussai F, Egan S, Hunter S, Webber H, Fisher J, Wheat R, et al. Neuroblastoma arginase activity creates an immunosuppressive microenvironment that impairs autologous and engineered immunity. Can Res. 2015;75(15):3043-53.

47. Guo Y, Ye Q, Deng P, Cao Y, He D, Zhou Z, et al. Spermine synthase and MYC cooperate to maintain colorectal cancer cell survival by repressing Bim expression. Nat Commun . 2020;11(1):3243.

48. Tabib A, Bachrach U. Activation of the proto-oncogene c-myc and c-fos by c-ras: involvement of polyamines. Biochem Biophys Res Commun. 1994;202(2):720-7.

49. Liu L, Rao JN, Zou T, Xiao L, Wang PY, Turner DJ, et al. Polyamines regulate c-Myc translation through Chk2-dependent HuR phosphorylation. Mol Biol Cell. 2009;20(23):4885-98.

50. Kumar N, Basundra R, Maiti S. Elevated polyamines induce c-MYC overexpression by perturbing quadruplex-WC duplex equilibrium. Nucleic Acids Res. 2009;37(10):3321-31.

51. Li L, Mao Y, Zhao L, Li L, Wu J, Zhao M, et al. p53 regulation of ammonia metabolism through urea cycle controls polyamine biosynthesis. Nature. 2019;567(7747):253-6.

52. Ou Y, Wang SJ, Li D, Chu B, Gu W. Activation of SAT1 engages polyamine metabolism with p53-mediated ferroptotic responses. Proc Natl Acad Sci USA. 2016;113(44):E6806-12.

53. Chae YB, Kim MM. Activation of p53 by spermine mediates induction of autophagy in HT1080 cells. Int J Biol Macromol. 2014;63:56-63.

54. Koomoa DL, Borsics T, Feith DJ, Coleman CC, Wallick CJ, Gamper I, et al. Inhibition of S-adenosylmethionine decarboxylase by inhibitor SAM486A connects polyamine metabolism with p53-Mdm2-Akt/protein kinase $B$ regulation and apoptosis in neuroblastoma. Mol Cancer Ther 2009;8(7):2067-75.

55. Bhattacharya S, Ray RM, Johnson LR. Role of polyamines in p53-dependent apoptosis of intestinal epithelial cells. Cell Signal. 2009;21(4):509-22.

56. Zou T, Mazan-Mamczarz K, Rao JN, Liu L, Marasa BS, Zhang AH, et al. Polyamine depletion increases cytoplasmic levels of RNA-binding protein HuR leading to stabilization of nucleophosmin and p53 mRNAs. J Biol Chem . 2006;281(28):19387-94.

57. Shantz LM. Transcriptional and translational control of ornithine decarboxylase during Ras transformation. Biochem J. 2004;377(Pt 1):257-64.

58. Origanti S, Shantz LM. Ras transformation of RIE-1 cells activates capindependent translation of ornithine decarboxylase: regulation by the Raf/MEK/ERK and phosphatidylinositol 3-kinase pathways. Can Res. 2007;67(10):4834-42.

59. Roy UK, Rial NS, Kachel KL, Gerner EW. Activated K-RAS increases polyamine uptake in human colon cancer cells through modulation of caveolar endocytosis. Mol Carcinog. 2008;47(7):538-53.

60. Hurta RA, Huang A, Wright JA. Basic fibroblast growth factor selectively regulates ornithine decarboxylase gene expression in malignant $\mathrm{H}$-ras transformed cells. J Cell Biochem. 1996;60(4):572-83.

61. Hurta RA, Lee J, Voskas D. Transformation by H-ras can result in aberrant regulation of ornithine decarboxylase gene expression by transforming growth factor-beta(1). J Cell Biochem. 2001;81(1):39-55.

62. Voskas D, Kim M, Hurta RA. Platelet-derived growth factor mediated altered expression and regulation of ornithine decarboxylase in $\mathrm{H}$-rastransformed cell lines. Cell Signal. 2001;13(6):401-9.

63. Hurta RA, Wright JA. Ornithine decarboxylase gene expression is aberrantly regulated via the CAMP signal transduction pathway in malignant H-ras transformed cell lines. J Cell Physiol. 1994;161(2):383-91.

64. Hardin MS, Hurta RA. Growth factor-mediated altered expression and regulation of S-adenosylmethionine decarboxylase in a $\mathrm{H}$-ras transformed cell line capable of malignant progression. J Cell Biochem. 2002;84(2):349-58.

65. Davies H, Bignell GR, Cox C, Stephens P, Edkins S, Clegg S, et al. Mutations of the BRAF gene in human cancer. Nature. 2002;417(6892):949-54.

66. Solit DB, Rosen N. Resistance to BRAF inhibition in melanomas. N Engl J Med. 2011;364(8):772-4.

67. Peters MC, Minton A, Phanstiel Iv O, Gilmour SK. A Novel PolyamineTargeted Therapy for BRAF Mutant Melanoma Tumors. Med Sci (Basel) . 2018;6(1):3. 
68. Hayes CS, DeFeo K, Lan L, Paul B, Sell C, Gilmour SK. Elevated levels of ornithine decarboxylase cooperate with Raf/ERK activation to convert normal keratinocytes into invasive malignant cells. Oncogene. 2006;25(10):1543-53.

69. Wang PY, Rao JN, Zou T, Liu L, Xiao L, Yu TX, et al. Post-transcriptional regulation of MEK-1 by polyamines through the RNA-binding protein HuR modulating intestinal epithelial apoptosis. Biochem J. 2010;426(3):293-306.

70. Ye Z, Zeng Z, Shen Y, Yang Q, Chen D, Chen Z, et al. ODC1 promotes proliferation and mobility via the AKT/GSK3 $\beta / \beta$-catenin pathway and modulation of acidotic microenvironment in human hepatocellular carcinoma. Onco Targets Ther. 2019;12:4081-92.

71. Dai F, Yu W, Song J, Li Q, Wang C, Xie S. Extracellular polyamines-induced proliferation and migration of cancer cells by ODC, SSAT, and Akt1-mediated pathway. Anticancer Drugs. 2017;28(4):457-64.

72. Kucharzewska P, Welch JE, Svensson KJ, Belting M. The polyamines regulate endothelial cell survival during hypoxic stress through PI3K/AKT and MCL-1. Biochem Biophys Res Commun. 2009;380(2):413-8.

73. Wang C, Ruan P, Zhao Y, Li X, Wang J, Wu X, et al. Spermidine/spermine $\mathrm{N} 1$-acetyltransferase regulates cell growth and metastasis via AKT/ $\beta$ catenin signaling pathways in hepatocellular and colorectal carcinoma cells. Oncotarget. 2017;8(1):1092-109.

74. Ray RM, Bavaria M, Johnson LR. Interaction of polyamines and mTOR signaling in the synthesis of antizyme (AZ). Cell Signal. 2015;27(9):1850-9.

75. Ray RM, Viar MJ, Johnson LR. Amino acids regulate expression of antizyme-1 to modulate ornithine decarboxylase activity. J Biol Chem . 2012;287(6):3674-90

76. Origanti S, Nowotarski SL, Carr TD, Sass-Kuhn S, Xiao L, Wang JY, et al. Ornithine decarboxylase mRNA is stabilized in an mTORC1-dependent manner in Ras-transformed cells. Biochem J. 2012;442(1):199-207.

77. Jiang R, Choi W, Hu L, Gerner EW, Hamilton SR, Zhang W. Activation of polyamine catabolism by N1, N11-diethylnorspermine alters the cellular localization of mTOR and downregulates mTOR protein level in glioblastoma cells. Cancer Biol Ther. 2007;6(10):1644-8.

78. Yan J, Yan JY, Wang YX, Ling YN, Song XD, Wang SY, et al. Spermidineenhanced autophagic flux improves cardiac dysfunction following myocardial infarction by targeting the AMPK/mTOR signalling pathway. Br J Pharmacol. 2019;176(17):3126-42.

79. Zabala-Letona A, Arruabarrena-Aristorena A, Martín-Martín N, FernandezRuiz S, Sutherland JD, Clasquin M, et al. mTORC1-dependent AMD1 regulation sustains polyamine metabolism in prostate cancer. Nature. 2017:547(7661):109-13.

80. Vaidya RJ, Ray RM, Johnson LR. MEK1 restores migration of polyaminedepleted cells by retention and activation of Rac1 in the cytoplasm. Am J Physiol Cell Physiol. 2005;288(2):C350-9.

81. Ray RM, Patel A, Viar MJ, McCormack SA, Zheng Y, Tigyi G, et al. RhoA inactivation inhibits cell migration but does not mediate the effects of polyamine depletion. Gastroenterology. 2002;123(1):196-205.

82. Mäkitie LT, Kanerva K, Andersson LC. Ornithine decarboxylase regulates the activity and localization of rhoA via polyamination. Exp Cell Res. 2009;315(6):1008-14.

83. Rao JN, Guo X, Liu L, Zou T, Murthy KS, Yuan JX, et al. Polyamines regulate Rho-kinase and myosin phosphorylation during intestinal epithelial restitution. Am J Physiol Cell Physiol. 2003;284(4):C848-59.

84. Asim M, Chaturvedi R, Hoge S, Lewis ND, Singh K, Barry DP, et al. Helicobacter pylori induces ERK-dependent formation of a phospho-c-Fos
c-Jun activator protein-1 complex that causes apoptosis in macrophages. J Biol Chem. 2010;285(26):20343-57.

85. Chaturvedi R, de Sablet T, Coburn LA, Gobert AP, Wilson KT. Arginine and polyamines in Helicobacter pylori-induced immune dysregulation and gastric carcinogenesis. Amino Acids. 2012;42(2-3):627-40.

86. Tomasi ML, Ryoo M, Skay A, Tomasi I, Giordano P, Mato JM, et al. Polyamine and methionine adenosyltransferase $2 \mathrm{~A}$ crosstalk in human colon and liver cancer. Exp Cell Res. 2013;319(12):1902-11.

87. Tu HC, Schwitalla S, Qian Z, LaPier GS, Yermalovich A, Ku YC, et al. LIN28 cooperates with WNT signaling to drive invasive intestinal and colorectal adenocarcinoma in mice and humans. Genes Dev. 2015;29(10):1074-86.

88. Park MH, Wolff EC. Hypusine, a polyamine-derived amino acid critical for eukaryotic translation. J Biol Chem. 2018;293(48):18710-8.

89. Wu F, Zhang Y, Sun B, McMahon AP, Wang Y. Hedgehog Signaling: From Basic Biology to Cancer Therapy. Cell Chem Biol . 2017;24(3):252-80.

90. Coni S, Di Magno L, Serrao SM, Kanamori Y, Agostinelli E, Canettieri G. Polyamine metabolism as a therapeutic target inhedgehog-driven basal cell carcinomaand medulloblastoma. Cells. 2019:8(2):150.

91. Lewis EC, Kraveka JM, Ferguson W, Eslin D, Brown VI, Bergendahl G, et al. A subset analysis of a phase II trial evaluating the use of DFMO as maintenance therapy for high-risk neuroblastoma. Int J Cancer. 2020. https://doi. org/10.1002/ijc.33044.

92. Messing E, Kim KM, Sharkey F, Schultz M, Parnes H, Kim D, et al. Randomized prospective phase III trial of difluoromethylornithine vs placebo in preventing recurrence of completely resected low risk superficial bladder cancer. J Urol. 2006;176(2):500-4.

93. Bailey HH, Kim K, Verma AK, Sielaff K, Larson PO, Snow S, et al. A randomized, double-blind, placebo-controlled phase 3 skin cancer prevention study of a-difluoromethylornithine in subjects with previous history of skin cancer. Cancer Prev Res. 2010;3(1):35-47.

94. Lynch PM, Burke CA, Phillips R, Morris JS, Slack R, Wang X, et al. An international randomised trial of celecoxib versus celecoxib plus difluoromethylornithine in patients with familial adenomatous polyposis. Gut. 2016;65(2):286-95.

95. Vlastos AT, West LA, Atkinson EN, Boiko I, Malpica A, Hong WK, et al. Results of a phase II double-blinded randomized clinical trial of difluoromethylornithine for cervical intraepithelial neoplasia grades 2 to 3 . Clin Cancer Res. 2005;11(1):390-6.

96. Einspahr JG, Nelson MA, Saboda K, Warneke J, Bowden GT, Alberts DS. Modulation of biologic endpoints by topical difluoromethylornithine (DFMO), in subjects at high-risk for nonmelanoma skin cancer. Clin Cancer Res . 2002;8(1):149-55.

97. Jeter JM, Curiel-Lewandrowski C, Stratton SP, Myrdal PB, Warneke JA, Einspahr JG, et al. Phase IIB Randomized Study of Topical Difluoromethylornithine and Topical Diclofenac on Sun-Damaged Skin of the Forearm. Cancer Prev Res (Phila). 2016;9(2):128-34.

98. Bartels P, Yozwiak M, Einspahr J, Saboda K, Liu Y, Brooks C, et al. Chemopreventive efficacy of topical difluoromethylornithine and/or triamcinolone in the treatment of actinic keratoses analyzed by karyometry ANA. Anal Quant Cytol Histol. 2009;31(6):355-66.

\section{Publisher's Note}

Springer Nature remains neutral with regard to jurisdictional claims in published maps and institutional affiliations. 